\title{
EFFECT OF SOME OPERATING CONDITIONS AMD GEOMETRY ON EFFECIENCY OF GAS FIRED FURNACE CHAMBER
}

\author{
M.B. MADI ${ }^{\star}$ A.H. ELASKARY ${ }^{\star \star}$ S.A. BELTAGUI ${ }^{\star}$
}

\section{ABSTRACT}

The study is concerned with the experimental investigation of the effect confinement ratio, swirl intensity and combustion intensity on heat transfer.

The experimental tests were carried out on nine swirlers with different geometry. The swirl burner was built in a combustion system which was equipped with the necessary regulating and measuring devices. The fuel employed was commerical grade butane.

The wall heat flux was obtained by direct measurement using a new technique for heat flux meter. Calculations of furnace efficiency were performed using numerical integration by Simpson's rule for heat flux distribution.

The results obtained showed that, a moderate amount of swirl in a highly confined furnace created a relatively large reverse flow zone and cause the flame to spread rapidly to the furnace wall, consequently changes in wall heat flux, and furnace efficiency were observed.

Correlation of data obtained may be useful for realising proper running of combustion systems and assisting to achieve optimal design for new combustion system.

\section{INTRODUCTION}

The efficiency and heat transfer distribution in furnace combustion chamber involves such a complicated interaction among the energy terms associated with heat transfer, combustion and flow pattersn. These terms should be controlled according to a specified requirements.

The conventional method used to control the flame dimensions and its stability is swirling the combustion air or by bluff bodies, positioned normally to the main stream, to creat inner recirculation zone. Some other methos are by restricting the exit section of the furnace [1]. This will lead to an improvement of mixing. Voriation of the degree of swirl

* Alex. University Faculty of Engineering, Mechanical Power Department.

* Menoufia University, Faculty of Engineering, Mechanical Department. 
intensity or/and confinement ratio will lead to an improvement of mixing, combustion and consequently furnace efficiency.

When a different diameters and swirl angles of burner are used to produce a flame in the same furnace, the resultant change in flow and combustion in the furance space may be considered under two categories:

a) The development of the flame jet may be almost unaffected by the change in confinement ratio. When an enclosed flame is fired with small swirl intensity in furnace of relatively large lateral dimensions (high confinement ratiol, it's development in terms of the entraiment of surrounding gases, and the spread of the flame may be considered by analogy of that of a free jet flame. Small change in burner diameter or swirl angle may change the volume of externally recirculating gases, but will have relatively little effect on jet expansion, and will only lead to problems of flame impingement for slowly mixing long flames.

b) The development of the flame is modified by the change in confinement ratio or/and swirl angle. As a result of the serious reduction in the combustion space available for external recirculation when the burner diameter becomes relatively large, and the problem of flame impingement may be further aggravated by the tendency for the flame to spread rapidly to fill the ovailable furnoce.

For many years the aircraft gas turbine combustor was designed by experience and as a consequence required, as a rule, an expensive development program. Recentely, however, it has become common to employ semi-emperical techniques to size the combustor so as to meet a wide range of operating conditions. The success of this has been such that there has been considerable intensification of the search for more accurate model, particularly with respect to defining furnace efficiency and heat flux distribution [2], [3] and [4].

The objective of this investigation is to present experimental data on the heat transfer behaviour of swirling flomes of different confinement ratios to relate the heat flux distribution and furnace efficiency in the cylindrical tested furnace to flow and combustion phenomena described. Improved understanding can minimize capital and runing cost by restricting the overall size of the combustion system.

\section{DESCRIPTION OF THE EXPERIMENTAL. ARRANGEMENT}

All tests referred to this work were conducted in an instrumented water-cooled horizontal cylindricial furnace. The facility design was based on some particular consideration, such as variable burner diameter to invetigate the effect of confinement ratio. Fig. (1) gives details of the test rig.

\subsection{The Combustor Test Facility}

The test rig which was used in this work comprised a horizontal furnace. This furnace was designed and constructed in Alexandria University. It consists of a flame tube of $257 \mathrm{~mm}$ inner diameter and $1430 \mathrm{~mm}$ long. The furnace chamber was cooled by water flowing into helical groove arround the outer wall, then it was well insulated.

\subsection{Burner Configuration}

The experimental program was carried out using the swirl burner type of MATHUR and MACCALLUM [5]. Comstruction details of the burnerased ore shom in Fig. (2). 


\subsection{Fuel and Fuel Supply System}

The trial was performed using commerical grade butane, which was composed of iso-and normal butane $\left(\mathrm{C}_{4} \mathrm{H}_{10}\right)$ fuels with small amount of other gaseous hydrocarbons. The tests were carried out with a fuel input of 2,5 $\mathrm{Kg} / \mathrm{hr}(22 \mathrm{Kw}$ firing) at approximately stoichiometric input conditions.

In the mixing section, butane fuel was introduced axially through 3 holes, down-stream, gas injectors, mounted to bluff plate. The function of this plate was to create a depression down-stream, which allowed the gaseous fuel to discharge into the high pressure air stream. The fuel rate was measured by a rotameter.

\subsection{Air Supply System}

The required air was supplied from an air blower. Air flow rate was measured through a calibrated orifice meter. Measuring devices for air flow rate, pressure and discharge regulation equipment were fitted at suitable location as shown in Fig. (1).

The exhaust gases were discharged from the furnace through the forced draft caused by the air blower. This maintained the pressure in the furnace chamber slightly above atmospheric pressure.

Heat flux measurements were carried out using ten calibrated heat flux meters (HEM's) which were installed along one furnace side. Construction details and caliberation are given elsewhere [6].

Temperature measurements were carried out by a platinum Rhodium VS platinum cal iberated the rmocouple.

The terminals of the (HFM's) and thermocouples were connected to a chart recorder through selector switch.

The test program of this investigation are summarized in Table (1)

\begin{tabular}{|c|c|c|c|c|c|c|c|c|c|}
\hline $\begin{array}{r}\text { Test } \\
\text { series }\end{array}$ & $\begin{array}{l}\text { Run } \\
\text { No. }\end{array}$ & $\varphi$ & 5 & $\begin{array}{l}\text { Run } \\
\text { No. }\end{array}$ & $\varphi$ & S & $\begin{array}{l}\text { Run } \\
\text { No. }\end{array}$ & $\varphi$ & S \\
\hline $\begin{array}{l}\text { "A" } \\
R e=50 \times 10^{3} \\
D / d=2.532\end{array}$ & $\begin{array}{l}(1) \\
(2) \\
(3)\end{array}$ & $\begin{array}{l}0.9 \\
1.0 \\
1.14\end{array}$ & $\begin{array}{l}0.95 \\
0.435 \\
0.435\end{array}$ & $\begin{array}{l}(4) \\
(5) \\
(6)\end{array}$ & $\begin{array}{l}0.9 \\
1.0 \\
1.14\end{array}$ & $\begin{array}{l}0.606 \\
0.606 \\
0.606\end{array}$ & $\begin{array}{l}(7) \\
(8) \\
(9)\end{array}$ & $\begin{array}{l}0.9 \\
1.0 \\
1.14\end{array}$ & $\begin{array}{l}1.051 \\
1.081 \\
1.051\end{array}$ \\
\hline $\begin{array}{l}\text { "B" } \\
R e=50 \times 10^{3} \\
D / d=3.367\end{array}$ & $\begin{array}{l}(10) \\
(111) \\
(12)\end{array}$ & $\begin{array}{l}0.9 \\
1.0 \\
1.14\end{array}$ & $\begin{array}{l}0.332 \\
0.332 \\
0.332\end{array}$ & $\begin{array}{l}(13) \\
(14) \\
(15)\end{array}$ & $\begin{array}{l}0.91 \\
1.0 \\
1.14\end{array}$ & $\begin{array}{l}0.464 \\
0.464 \\
0.464\end{array}$ & $\begin{array}{l}(16) \\
(17) \\
(18)\end{array}$ & $\begin{array}{l}0.91 \\
1.0 \\
1.14\end{array}$ & $\begin{array}{l}0.803 \\
0.800 \\
0.803\end{array}$ \\
\hline $\begin{array}{l}\text { "C" } \\
D / d=5.78\end{array}$ & $\begin{array}{l}(19) \\
(20) \\
(21)\end{array}$ & $\begin{array}{l}0.92 \\
1.03 \\
1.14\end{array}$ & $\begin{array}{l}0.303 \\
0.303 \\
0.303\end{array}$ & $\begin{array}{l}(22) \\
(23) \\
(24)\end{array} \mid$ & $\begin{array}{l}0.92 \\
1.03 \\
1.14\end{array}$ & $\begin{array}{l}0.423 \\
0.423 \\
0.423\end{array}$ & $\begin{array}{l}(25) \\
(26) \\
(27)\end{array}$ & $\begin{array}{l}0.92 \\
1.03 \\
1.14\end{array}$ & $\begin{array}{l}0.782 \\
0.732 \\
0.732\end{array}$ \\
\hline
\end{tabular}




\section{EXPERIMENT RESULTS AND DISCUSSION}

Preliminary description of the flame behaviour produced for the burner geometries employed $[(D / d)=5,78,3,36$ and 2.53 and $(S)=0,32,0.44$ and 0.77 fell into both categories defined in section 1.A strong internal reverse flow zone existed on the burner axis, which carried hot combustion products back into the burner mouth to stabilized combustion there. The mixing of fuel and air was rapid and resulted in an intense blue flame. The flame geometry was changed when the burner geometries were changed.

It was clear that the change in the flow pattern due to the variation of the above mentioned parameters, had an important effect on the heat flux distribution alorig the furnace. The results shown in Figs $(3,4$ and 5 ) display sample of measured total heat flux distribution $\left(q_{t}\right)$ at various locations along the furnace axis $(x)$. The effect of equivalence ratio $(\varphi)$, swirl number (S) and confinement ratio (D/d) is considered. All tests were carried out at nearly constant Reynolds number $(\operatorname{Re})=50000$, based on burner diameter (d).

It can be observed that the location of the maximum heat flux was varried according to the value of $(S)$ and $(D / d)$.

The following general remarks were deduced from figs (3 through 8) concerning total heat flux distribution and furnace efficiency:

\section{1 Total Heat Flux Distribution $\left(q_{t}\right)$}

It can be observed from Figs (3 through 5) that most of the heat is released in a short upstream distance compared with the total flame length, as the main heat transfer by convection will be relatively high due to the impinging of the flame jet on the furnace wall in this section.

\subsubsection{Effect of Equivalence Fuel-Air Ratio ( $\varphi$ )}

The heat transferred to the furnace wall depends on the flame temperature and emissivity. Since these quantities influenced by the change in $(\varphi)$, it is expected that the heat flux distribution should influence also by ( $\varphi)$.

For the flame No. 10, 11, 12, see Fig. (3), the heat flux distribution was fairly even. And maximum value was located at $(x / 0) \simeq 0.8$ which is nearly $1 / 7$ th furnace length.

The location of ( $\left.q_{\text {max }}\right)$ not effected by changing the value of ( $\infty$ ). But higher value of $\left(q_{m a x}\right)^{\text {waxs }}$ observed at $\varphi=1$ and decreases when the value of $(\varphi)$ is less or higher than 1.

\subsubsection{Effect of Swire Number (S):}

The effect of (S) on total heat flux distribution $\left(q_{t}\right)$ is shown in Fig. (4). It is evident that at constant ( $\varphi$ ) and ( 0 bl) when the swirl number was increased, the increase in size of CRZ was accompanied by greater jet spread. Strong velocity components were now clearly directed to the walls causing on increase in convective reot transfer mode.

For flame with $\dot{S}=0,732$, the total heat flux were at some what higher 
value for the greater part of the furnace, presumably because of the high velocities generated by the swirl action along the walls and the enhance of mixing and combustion.

At the region where flame impinging on the wall took place, a peak value of $(105 \mathrm{kw} / \mathrm{m})$ was found. Such an increase in convective heat transfer is similar to the effect of flame impinging [7].

Decreasing swirl number led to slow expansion of the flame jet and to the existance of a large weake internal reverse flow zone filling most of the furnace section. Consequently the value of maximum heat flux decreases and the impact point moves downstream towards higher value of $(x / D)$. This effect is characterized by a shorter and higher temperature flame due to reterlation of the reaction zone near the burner vicinity as (S) increases.

\subsubsection{Effect of Confinement Rotio (D/d)}

The effect of burner diameter or $(D / d)$ on total heat flux distribution is shwon in Fig. (5). It is evident that at constant ( $\varphi)$ and (S), the total heat flux to the furnace wall is significantly affected by the confinement ratio (D/d). Total heat flux increases as the rate $(D / d)$ increases. This effect can be attributed to the increase of gas radiation, owing to the higher beam length, the actual extent of this increase being greater for lower initial value of emissivity as observed in the other runs. This increase in gas emissivity has an extent beyond which its value is reduced. That is because the increase in emissivity and hence the radiation heat transfer mode is encouraged at a certain temperature level after which its value falls down and the convective heat transfer mode increases.

It is also obvious that increasing the confinement ratio leads to the movement of the impact point upstream towards the burner vicinity.

\section{FURNACE EFFICIENCY $\left(\eta_{f}\right)$}

The experimental results for the total heat flux distribution along the furnace axis were used to estimate the furnace efficiency $n_{F}$. Calculations of $\left(n_{F}\right)$ were performed using numerical integration. The results shown in Figs $(6,7$ and 8$)$ illustrate calculated furnace efficiency for different operating conditions $(\varphi, S$ and $D / d)$. The following observations are apparent from these results:

i. For constant (S) and (D/d), see Fig (6), the furnace efficiency $\left(\eta_{f}\right)$ increases with the increase of equivalence ratio $(\varphi)$, until it reaches $f^{\prime}$ ts maximum value at arround $(\varphi)=1$.

ii. For constant $(\varphi)$ and (D/d), see Fig. (7), the furnace efficiency increases, with a small rate by increasing swirl intensity. For $(D / d)=$ 2.53 and $(\varphi)=1.14$, the furnace efficiency increases by $40 \%$ when changing (S) from 0.318 to 0.773 .

iii.For constant $(\varphi)$ and (S), see Fig. (8), the furnace efficiency increases, with a higher rate, by increasing confinement ratio (D/d). For $(s)=0.32$ and $(\varphi)=1,03$, the furnace efficiency increases by $80 \%$ when changing (D/d) from 2.53 to 5.78 .

These results were generalized in an emperical formula, which given by:
$n_{F}=$
$=10.047 \varphi+0.75$
$\varphi^{2}-0.41$
(3)
$(D / d)^{0.18}$
(s) 0.105 


\section{CONCLUSIONS}

An analysis of experimental data on total heat flux distribution and furnace efficiency, for the present work, has led to the following results:

1. Total heat flux, from a confined flame to the furnace wall, can be controlled fairly well by varying the confinement ratio, in addition to the conventional method of changing the swirl intensity and equivalence ratio.

2. Extensive measurements of total heat flux produced by various configura tion and operating condition of swirl burner have been corrected with a view to aiding the design of combustion systems. The results have led to the following imperical formula for furnace efficiency:

$$
n_{F}=\left(0.047 \varphi+0.75 \varphi^{2}-0.41 \varphi^{3}\right)(D / d)^{0.18}(S)^{0.105}
$$

\section{REFERENCES}

1. LONGWELL J.P. "Flame Stabilization by Bluff Bodies and Turbulent Flames in Ducts" 4th Symp. on Combustion No. 8. pp. 90-97.

2. ABD El-All M.M. "Heat and Mass Transfer in Furnaces" Ph.D. Thesis, Alex。 Un. 1987.

3. SAYRED N. and DAHMAN K.R "Effect of High Levels of Confinement upon Aerodynamics of Swirl Burners". J. Energy. Vol. 2 No.l pp. 8-15 1978.

4. MORSY, B.K "Effect of Some Geometrical and Operating Conditions on Heat Liberation in a Gas Fired Cylindrical Chamber" M.Sc. Thesis. Minia Univ. 1983.

5. MATHUR M.L. and MACCALUM N.R.L "Swirling Air Jets Issuming from Vane Swirl" J. Inst of Fuel-Vol 40 pp 238-245, 1967.

6. MADI M.B., BELTAGUI S.A., ELASKARY A.H. and ABDELALL M.M. "An Instrument For the Direct Measurement of Radiotion and Total Heat Flux" The Bull. of Alex. Unv. Faculty of Eng. vol XXV 1986.

7. MADI, M.B. and ELASKARY, A.H "Heat Transfer Calculation in Furnaces of High Levels of Confinement" The Bull. of Alex. Unv. Foculty of Eng. vol. XXV 1986.

\section{NOMENCLATURE}

D furnace diameter.

d burner diameter.

q. total heat flux

$x^{t}$ axial distance from burner exit.

5 swirl number.

\% equivalent fuel-air ratio.

$\eta_{f}$ furnace efficiency. 

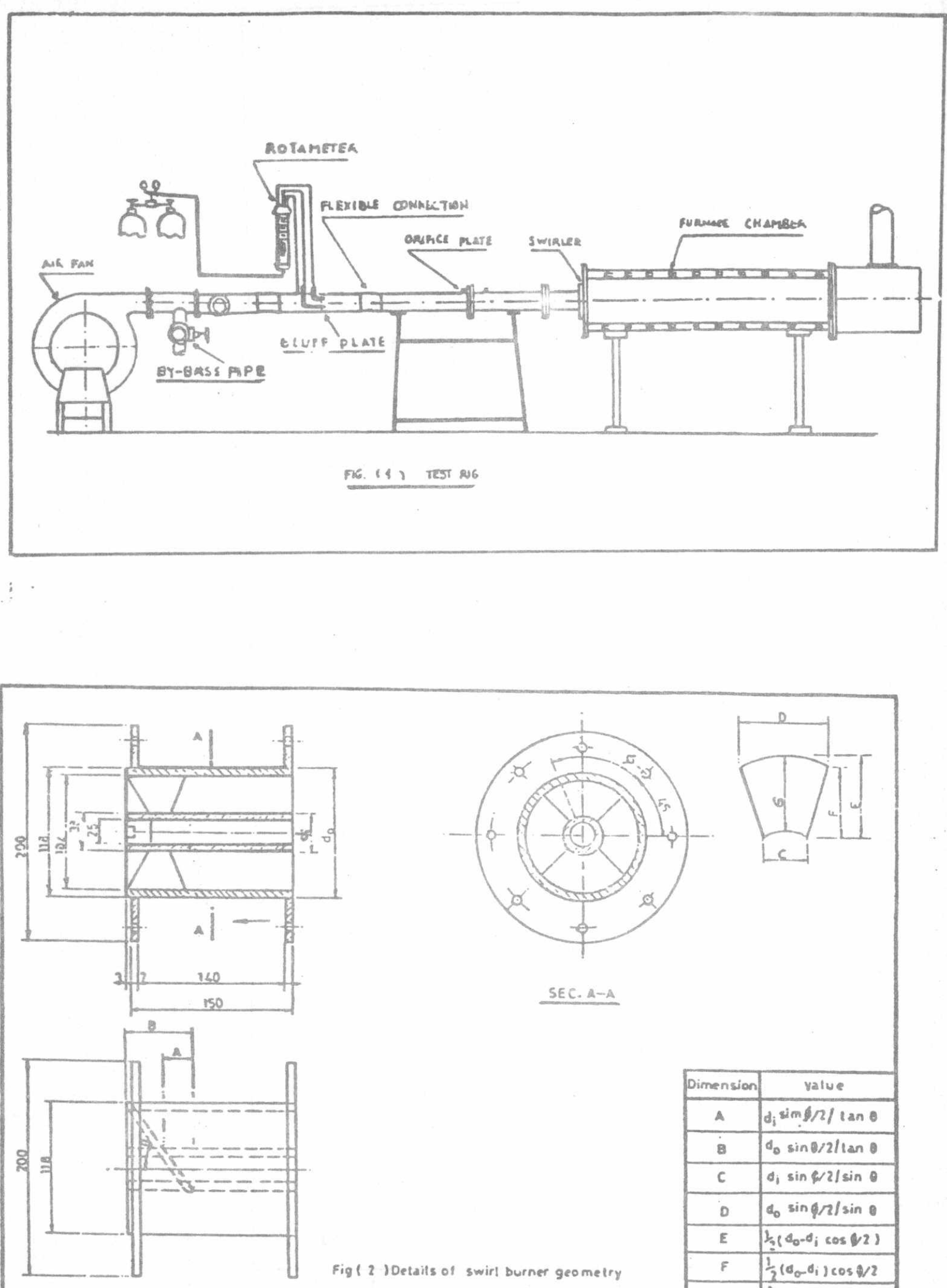

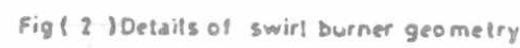
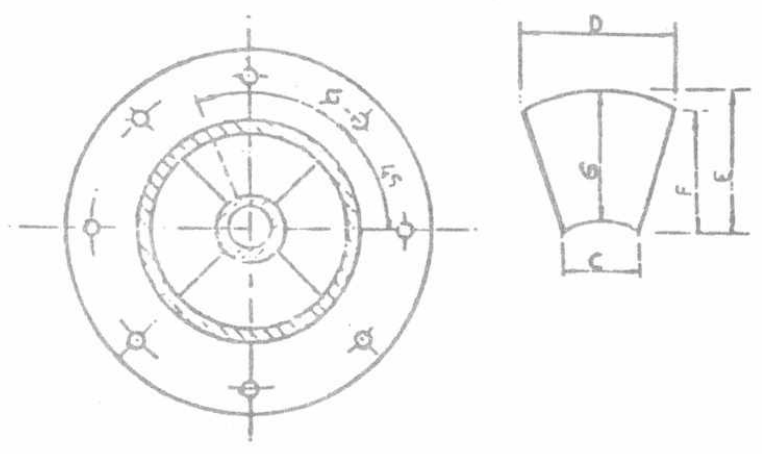

SEC. A-A

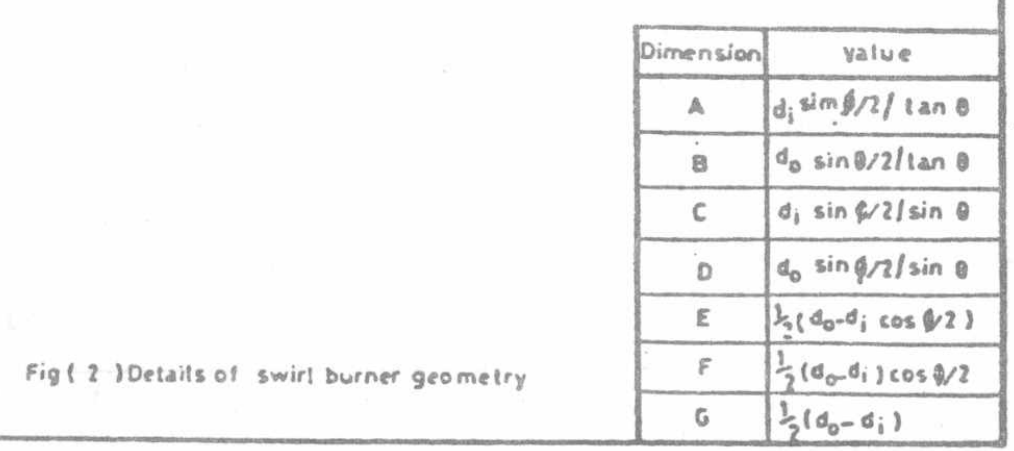




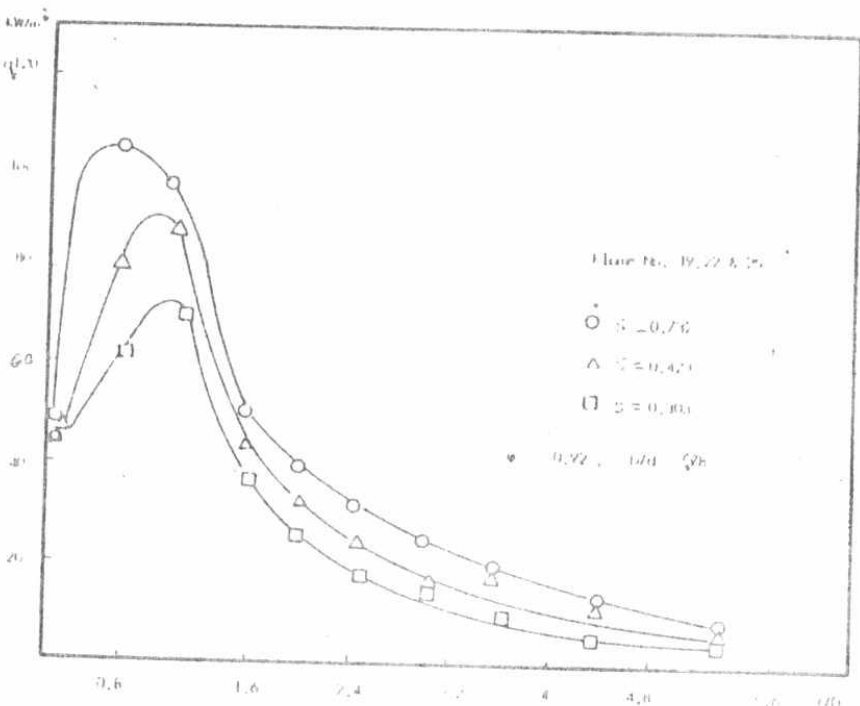

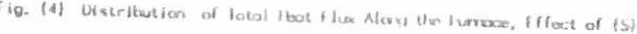

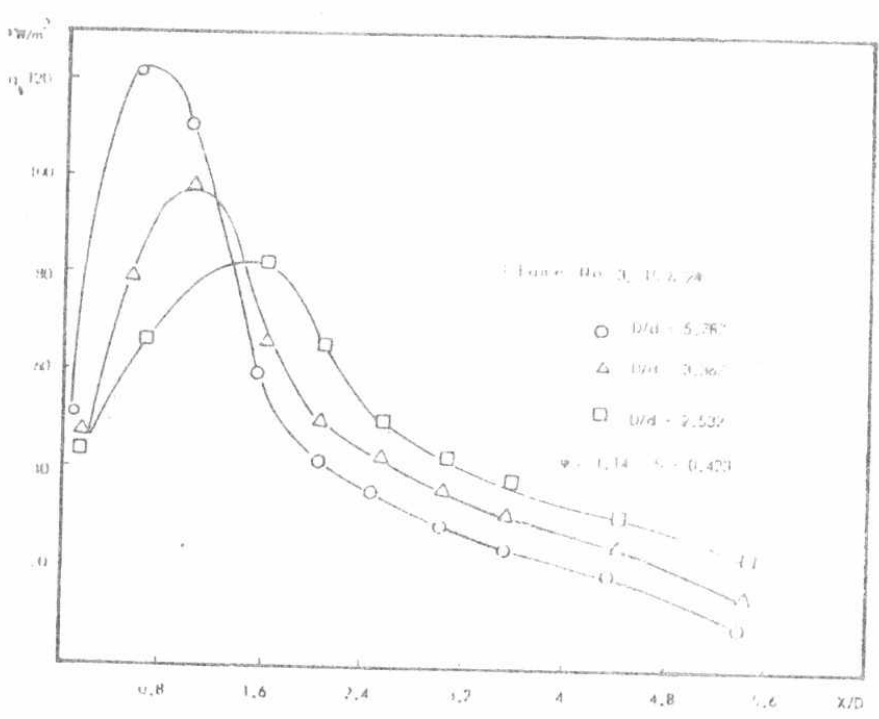

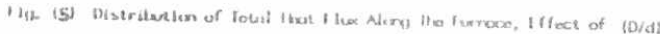

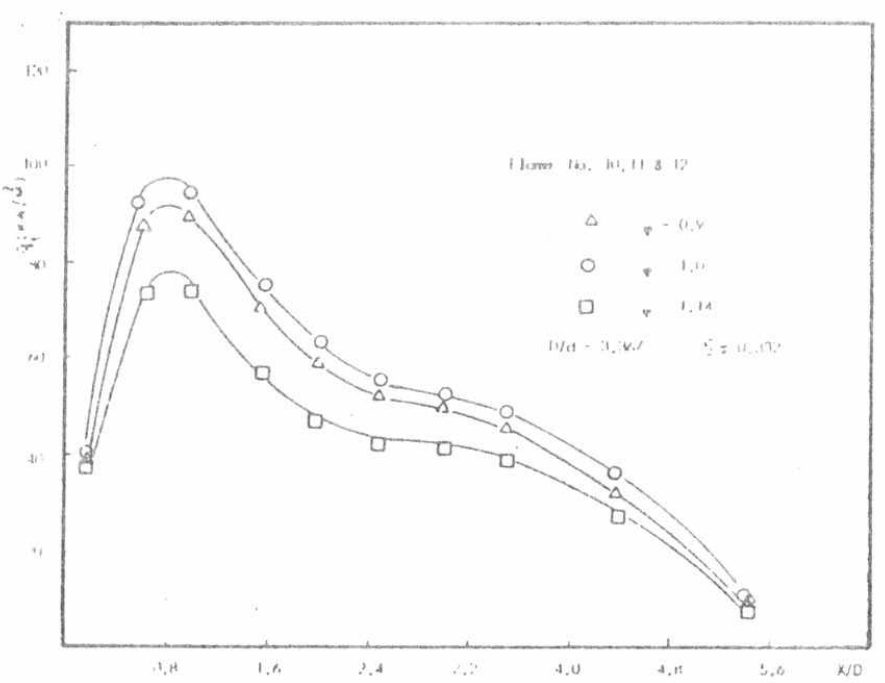

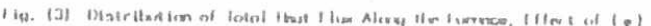


$r$

6
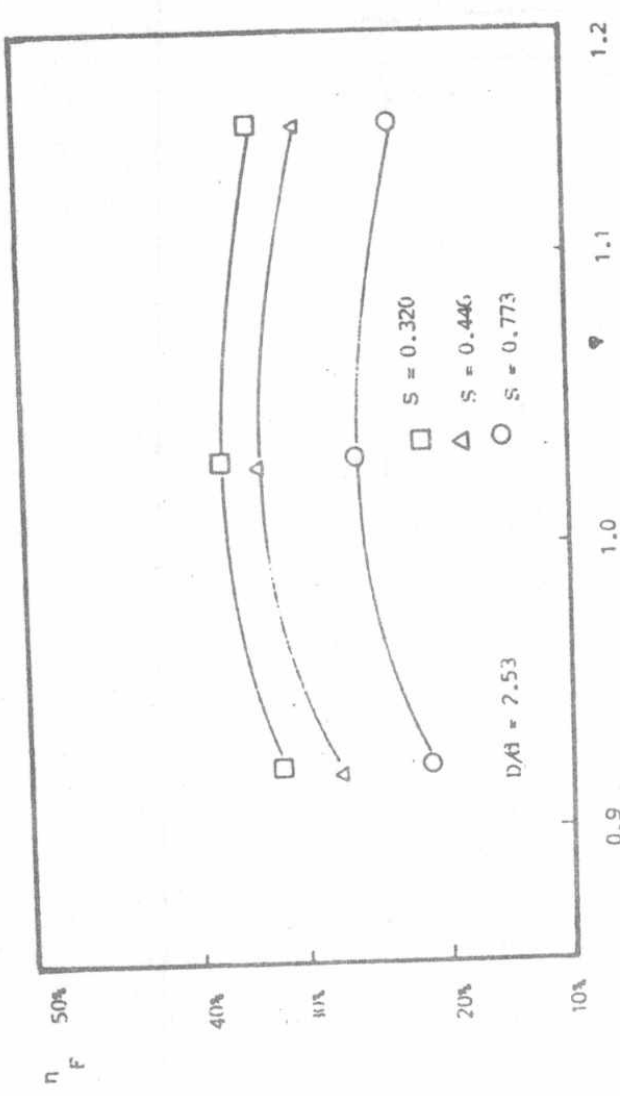


\section{$r$}

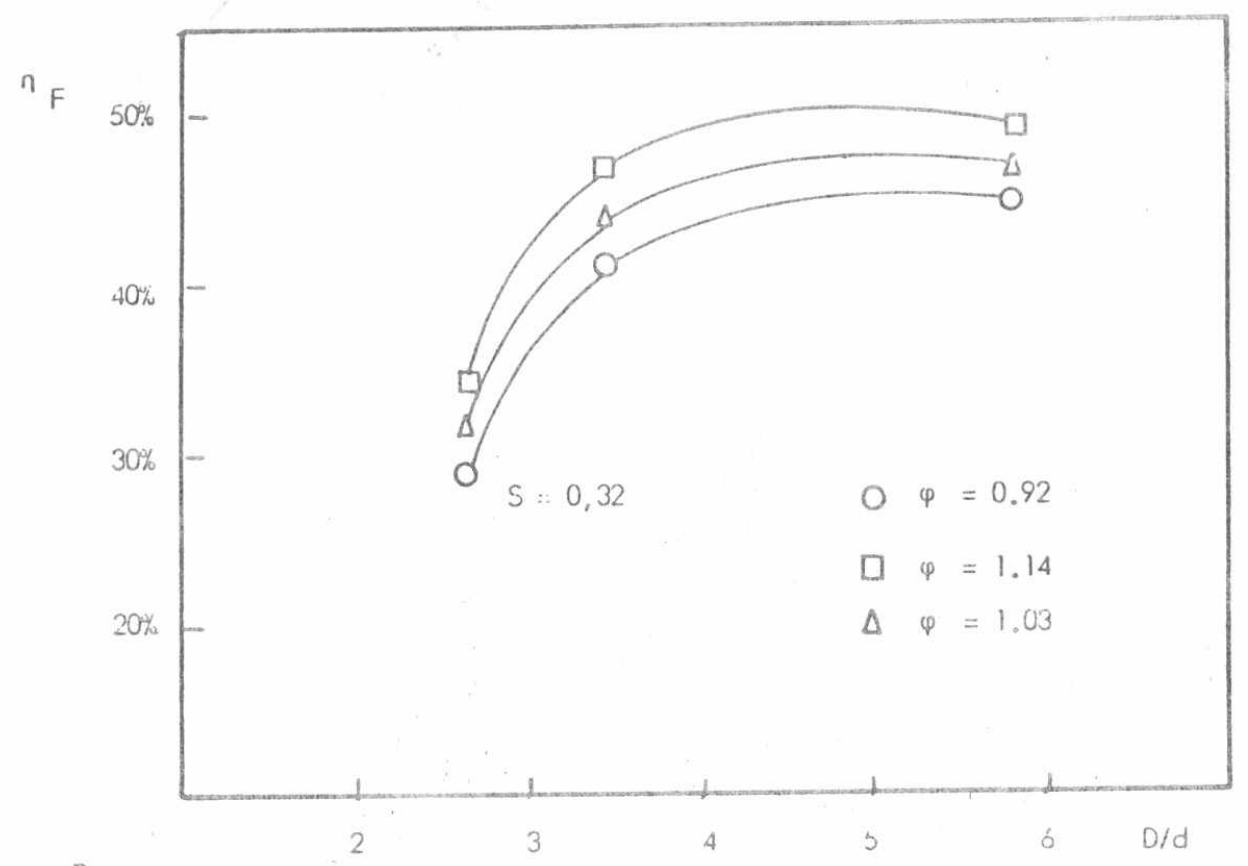

$\eta$
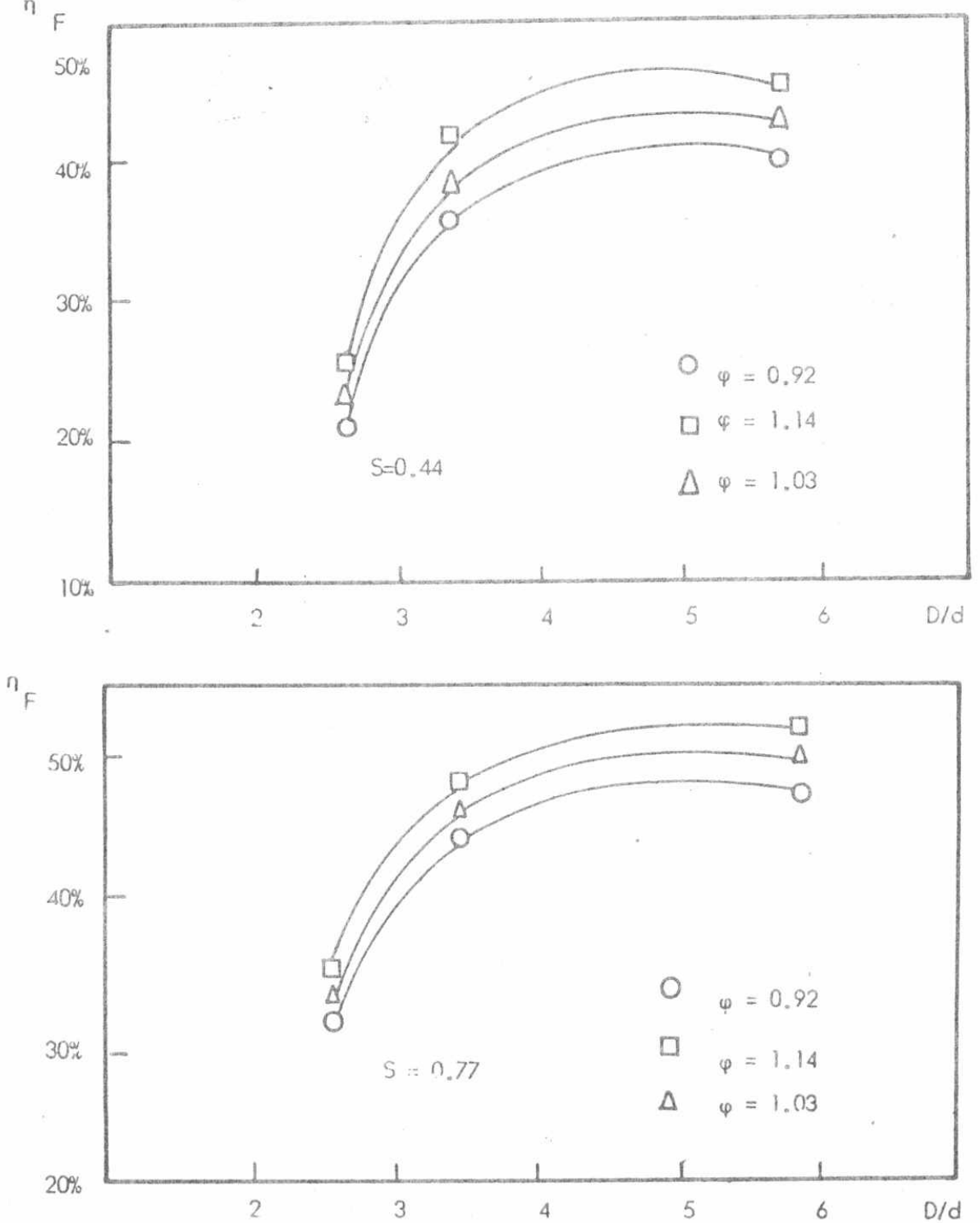

Fig. (8) Effect of Confinement Rotio (D/d) an [umoce Efficiency $(n$, , 